\title{
Preface to the MME Special Focus Issue in Memory of Emeritus Professor Frank F. Aplan: Between Theory and Practice
}

\author{
Barbara J. Arnold ${ }^{1}$
}

Published online: 3 January 2022

(c) Society for Mining, Metallurgy \& Exploration Inc. 2021

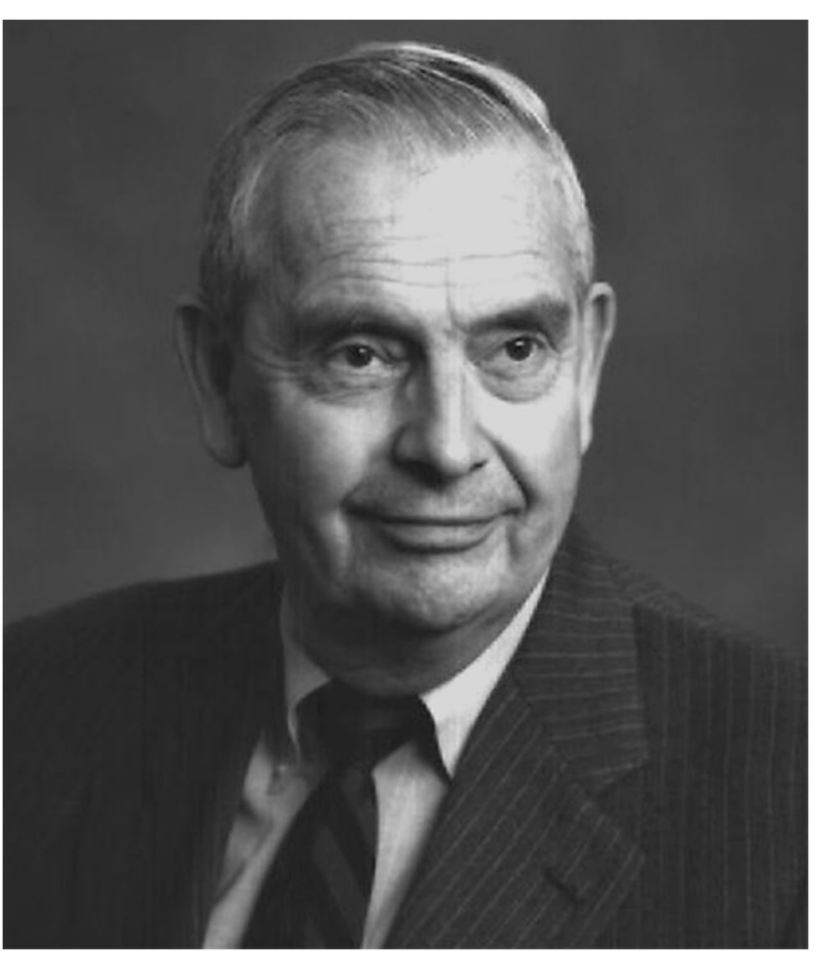

Frank F. Aplan, the son of Frank F. Aplan Sr. and Helen Fischer Aplan, was born August 11, 1923, in Boulder, Colorado. He was raised in Fort Pierre, South Dakota, during the decade-long Depression, drought, and plague of grasshoppers of the 1930s. In 1941, he entered the South Dakota School of Mines and Technology (SDSM\&T). World War II interrupted his education as he enlisted in the Army in November 1942. He served as an infantryman in a rifle company of the 69th Infantry Division in Europe and received

Barbara J. Arnold

bja4@psu.edu

1 Mining Engineering, The Pennsylvania State University, University Park, PA, USA the Combat Infantrymen's Badge and Bronze Star Medal. Following his discharge from the Army, he re-entered SDSM\&T in 1946 and earned a B.S. degree in Metallurgical Engineering in 1948. He then received an M.S. from Montana Tech (MT), worked several years in industry and then as an Assistant Professor at the University of Washington (Seattle). He joined his Montana Tech colleague, Douglas W. Fuerstenau, at The Massachusetts Institute of Technology (MIT), receiving his doctorate in 1957. While at MIT, he married Clare M. Donaghue of Dorchester, Massachusetts, in 1955 [1].

I've been asked many times if Dr. Aplan was one of Antoine Gaudin's students at MIT. Gaudin was the section head in Mineral Engineering at the time, and Dr. Aplan worked on two of the chapters in Gaudin's mineral processing books. Phil deBruyn was Dr. Aplan's lead advisor, with Reinhard Schuhmann, Carl Wagner, and J.TH.B. Overbeek also advising on the thermodynamic analysis of adsorption of collectors on surfaces in the mercaptan/gold system [2]. A softbound copy of his thesis is among his papers and books. I swear, it smells like mercaptans!

After receiving his Sc.D., Dr. Aplan worked for five different mining, metallurgy, and chemical companies, including Union Carbide where he served as Group Manager of the Mineral Engineering R\&D Group [1].

In 1968, he joined The Pennsylvania State University as Professor and Head of the Department of Mineral Preparation, serving as Professor, Section Chair for Metallurgy and for Mineral Processing, and as Distinguished Professor until his retirement in 1992. He continued his teaching and research for the next decade. He specialized in ore and coal processing and environmental pollution control and was especially proud of his nearly 50 graduate students [1].

Dr. Aplan held memberships in the Society of Mining Engineers and the Metallurgical Society-now the Society for Mining, Metallurgy \& Exploration (SME) and the Minerals, Metals \& Materials Society (TMS), respectively—for over 65 years each, and the American Chemical Society 
(ACS) for over 50 years. He was an elected member of the National Academy of Engineering and an Honorary Member of the American Institute of Mining, Metallurgical and Petroleum Engineers (AIME), receiving their Robert $\mathrm{H}$. Richards and Mineral Industry Education Awards. He was a Distinguished Member (now Fellow) of SME, receiving their Antoine M. Gaudin and Arthur F. Taggart Awards. The Frank F. Aplan Award of AIME and the Engineering Foundation was named in his honor. He also held the joint SME/ American Society for Mechanical Engineers (ASME) Percy Nicholls Award. He was a Distinguished Alumnus of both SDSM\&T and MT and received Montana Tech's Chancellor's Medallion in 2015. He was elected to the South Dakota Hall of Fame in 1998, and was inducted into the National Mining Hall of Fame in 2016 [1].

Mentor ... an experienced and trusted advisor. We were blessed to have Dr. Frank F. Aplan as a mentor and friend for a very long time. He was 97 years young at his passing on November 3, 2020. I spoke with him on his birthday in August that year, and he was pleased to know that I'd be bringing much of the Aplan Library back to State College. With the COVID-19 pandemic, I have limited the books moved to State College since my office could be off-limits at any time. So, books on rare earths, other critical minerals, mineralogy, and colloids among other topics grace the shelves (and floors) of my home office there. You may think of Dr. Aplan for his applied research in coal froth flotation and tailings; but at Penn State, we always highlight one of his prescient papers on the processing of rare earth elements [3]. Of course, now that rare earth elements are being exploited from the coal measures, we find that all the topics in Dr. Aplan's 1992 Gaudin Lecture, "Coal Properties Dictate Coal Flotation Strategies," must be considered as we advance the concentration of these minerals from coal [4]. His guidelines for coal flotation in that lecture can certainly be applied to other fine coal (and associated mineral) processing technologies:

Know your coal.

Know the general geologic and geographic genesis and location information and the special properties associated with these circumstances.

Know the coal rank. From this, its physical and chemical properties may be inferred.

Know the sulfur content and forms-pyritic, organic and sulfate.

Consider any special circumstances, such as oxidation, pyrite and ash mineral constituents, their quantity, distribution and properties, and user constraints.

Know the strengths and weaknesses of the flotation processes and the reagents used.

Know the user constraints so that grade-yield trade-offs can be properly evaluated.
While this list doesn't specifically call out macerals (one of my favorite things to explore), they are featured in the lecture. I think he used some of my pictures!

His full oral history, entitled "Mineral Education Generalist, Professor of Metallurgy and Mineral Processing," is available on the internet by searching AIME Oral Histories. In memory of his many contributions to coal and mineral processing, he will be honored by a gathering of renowned engineers and scientists for two special sessions on "Frank F. Aplan: Between Theory and Practice" to be held in conjunction with the MINEXCHANGE 2022 SME Annual Conference \& Expo in Salt Lake City, Utah. He influenced his students and colleagues alike with his enthusiasm for living, love of jazz, wine and history, and passion for mineral processing, especially putting theory into practice. Much of his work was based on process mineralogy principles-knowing first the characteristics of the mineral or material and then understanding the appropriate processes for beneficiation. This special issue and the special sessions will include papers focused on applications of process mineralogy in the areas of the froth flotation of coal and ores, beneficiation of rare earth elements and other critical minerals, flocculation, heavy media separations, process design, and other related topics.

South Dakota School of Mines, Montana Tech and MIT; SME, TMS, ACS, National Academy of Engineering; South Dakota Hall of Fame, National Mining Hall of Fame... Education, associations, honors, awards... But always Frank F. Aplan - teacher, researcher, mentor, friend.

Dr. Aplan's students did many things because he said it would be "good for our soul!" We all know that he had a very hearty soul. And we know that he will rest in peace.

Special Focus Issue Guest Editor,

Barbara J. Arnold.

\section{References}

1. Koch Funeral Home (2021) Obituary of Frank Fulton Aplan. https://kochfuneralhome.com/tribute/details/2261/Frank-Aplan/ obituary.html. Accessed 6 Dec 2021

2. Swent, E (2003) Frank F. Aplan, Mineral Education Generalist, Professor of Metallurgy and Mineral Processing, 1951-1998, Western Mining in the Twentieth Century Series, Regional Oral History Office, The Bancroft Library, University of California, Berkeley, CA

3. Aplan, FF (1988) The Processing of Rare Earth Elements. In R.G. Bautiste and MM. Wong (Eds.) Rare Earths, Extraction, Preparation and Applications, The Minerals, Metals \& Materials Society

4. Aplan, FF (1993) Coal properties dictate coal flotation strategies. Mining Engineering, SME January 1993 pp. 83-96

Publisher's Note Springer Nature remains neutral with regard to jurisdictional claims in published maps and institutional affiliations. 